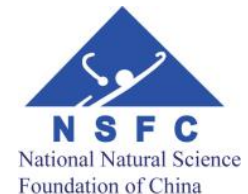

University
of Glasgow

UNIVERSITY of
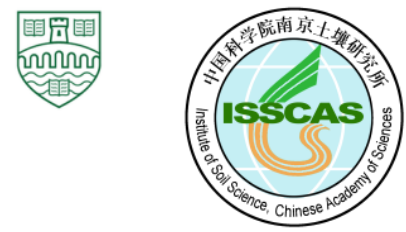

\title{
Report for the Yujiang Government on the China-UK Knowledge Exchange Project for the Red Soil Critical Zone
}

Ying Zheng ${ }^{\mathrm{a}}$, Larissa A. Naylor ${ }^{\mathrm{a}}$, Susan Waldron ${ }^{\mathrm{a}}$, David M. Oliver ${ }^{\mathrm{b}}$, Lei Gao $^{\mathrm{c}}$

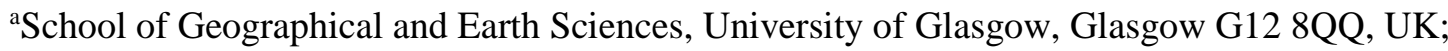

${ }^{b}$ Faculty of Natural Sciences, University of Stirling, Stirling, FK9 4LA, UK;

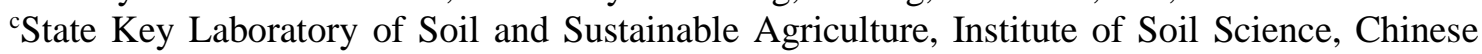
Academy of Sciences, Nanjing, 210008, PR China

Contact: Ying Zheng (Ying.Zheng@glasgow.ac.uk)

\begin{abstract}
:
Knowledge exchange (KE) has been increasingly used to translate the scientific findings to produce outputs that inform land users and policy makers to lead to the sustainable environmental management. As part of the wider China-UK Critical Zone (CZ) programme, a KE research project was conducted to help ensure research results can be more effectively delivered to those who need them. Following on the early stage of exploration in Guizhou's karst area, similar KE survey and interview research was carried out in Jiangxi's red soil landscape in March 2018. This research sought to understand the current ways in which Chinese leaders and farmers learn from scientists and what are key issues facing them that the red soil CZ research can help with. This report documents the findings of the needs of local farmers, their farming practices and understanding of landscape processes, along with learning preferences of different public groups (farmers and village, town and country leaders). A conceptual model of science-policy-practice interface was developed. This understanding, together with the KE findings in karst area, can provide valuable information for the future design of KE delivery and KE outputs arising from the $\mathrm{CZ}$ projects and those of others.
\end{abstract}

This is a non-peer reviewed report published at EarthArXiv. 


\section{Project aims}

This study was commissioned as part of the China-UK Critical Zone (CZ) Project for the 'From Natural and Anthropogenic Evolution of Red Soil and its Impact on Ecosystem Function in the Critical Zone'. This study explores what knowledge exchange activities can facilitate communication and understanding between academics and the non-academic groups of the red soil CZ science research in the context of Chinese culture, especially in China rural areas.

\section{Funders}

This publication was produced under grant NE/N007425/1 which was awarded by the Natural Environment Research Council (NERC) of the UK.

\section{Team \& Authors}

The project team consists of Prof. Susan Waldron (Principal Investigator), Dr. Larissa Naylor (Co-Investigator) and Dr. Ying Zheng (KE research associate) from the University of Glasgow, and Dr. David Oliver (Co-Investigator) from the University of Stirling.

This publication is produced by Ying Zheng, Larissa A. Naylor, Susan Waldron, David M. Oliver. and Lei Gao. It can be cited as: Zheng, Y., Naylor, L.A., Waldron, S., Oliver, D.M., Gao L. 2018. Report for the Yujiang Government on the China-UK Knowledge Exchange Project for the Red Soil Critical Zone. DOI: 10.31223/osf.io/4wpq9

Chinese Citation: 郑颖, Naylor, L.A., Waldron, S., Oliver, D.M. 高磊. 2018. 中英红壤关键带 研究余江县知识交流报告. DOI: 10.31223/osf.io/4wpq9

Author contribution: Y.Z., L.A.N. and S.W. conceived the presented study design. Y.Z. conducted the fieldwork, data acquisition and analysis. Y.Z., L.A.N., S.W. and D.M.O. drafted the report and provided critical revision. L.G. helped to refine the questionnaires and contributed to the final revision of the report.

\section{Acknowledgements}

The analysis draws on a survey conducted by the University of Glasgow, and assisted by Institute of Soil Science, Chinese Academy of Sciences (ISSCAS), Yingtan Farmland Ecosystem National Field Observation and Research Station (hereafter short for Yingtan Station).

Dr. Jianbo Fan, office director of Yingtan Station, provided valuable support in facilitating access to the local village leaders and residents surveyed. The local villager Qingtang Zhang and his friends offered great help to connect and conduct the surveys with farmers in the villages. Significant help also came from undergraduate students of East China University of Technology; they were trained by the UK researcher and then carried out surveys with local farmers. They explained the survey's aims and helped the local farmers complete the surveys. Dr. Joseph Oyesiku-Blakemore (University of Aberdeen) and Dr. Lucile Verrot (University of Aberdeen) provided helpful suggestion to refine the questionnaires. Many government officers and farmers actively participated in the surveys. Thanks also go to Dr. Neil Munro and Dr. Nai Rui Chng from University of Glasgow, who provided valuable help in designing the survey methods and advice in data analysis. 


\section{Executive summary}

This report is a first stage output from the Knowledge Exchange ${ }^{1}(\mathrm{KE})$ research package within the China-UK Critical Zone programme for the red soil project in Sunjia Catchment in Yujiang County, Jiangxi Province, China.

The critical zone (hereafter, CZ) is scientifically defined as the "heterogeneous, near surface environment in which complex interactions involving rock, soil, water, air, and living organisms regulate the natural habitat and determine the availability of life-sustaining resources" (National Research Council America, 20012). This portion of the Earth surface sustains nearly all terrestrial life and support almost all human activity ${ }^{2}$. The Red Soil CZ project in Yujiang County focuses on the natural and anthropogenic evolution of red soil and its impact on ecosystem function in the CZ. Part of the requirement of the research project is to translate the scientific findings to produce outputs that inform land users and policy makers to lead to the sustainable management of red soils. This new knowledge will help the local residents deal with current and future environment challenges through improving our understanding of the processes and pressures on critical ecosystem services ${ }^{3}$ this landscape (and the economic benefits of these) provides to society. Improved understandings of red soils and their interaction with the environment provides valuable data for policy decisions in China about the management of red soils.

To do this most effectively, we need to understand the current ways in which Chinese leaders, farmers and residents learn from scientists and what are key issues facing them that our research can help them with. Therefore, we need to first understand their current knowledge of the red soil landscape they live in and how their activities affect it. As part of the wider CZ programme, there is an on-going $\mathrm{KE}$ research project that is designed to help ensure research results can be more effectively delivered to those who need them. To facilitate more effective delivery of the research outputs from the red soil CZ project, we carried out a baseline survey in March 2018 to learn about the local residents, their needs, farming practices and understanding of landscape processes, along with the KE methods and preferences of different public groups (farmers and village, town and country leaders). This understanding can provide valuable information for the future design of KE delivery and KE outputs arising from our projects and those of others. The report introduces the project (Section 1), outlines the research methods (Section 2) and presents preliminary results from the KE survey (Sections 3, 4, 5 and 6), which was carried out in March 2018.

The survey results showed water quantity and/or quality for irrigation was the biggest concerns for Yujiang farmers (Section 3). Many of them did not have proper catchment knowledge or appear to poorly understand how their activities influenced catchment processes and surrounding environment, and thus their livelihoods (Section 4). Yet, the majority of farmers expressed a keen interest in learning about different farming and knowledge about red soil erosion and management practices - few of these felt that they had received much training in this regard. The lack of catchment knowledge and perceived lack of training by farmers suggests that there is a need of better KE with Yujiang farmers.

We asked the different survey groups how they felt farmers would best learn new skills and understanding of catchment processes to improve farm productivity and environmental sustainability at the same time - results differed between groups, mainly between farmers and

\footnotetext{
${ }^{1}$ Knowledge exchange (KE) is defined as the two-way process of shaping, sharing and the scientific research process so that the science produced can be readily used policymakers, practitioners and society (Fazey et al. 2013). KE largely focuses on identifying and overcoming the barriers to knowledge exchange between them (after Cvitanovic et al., 2015).

${ }^{2}$ Basic Research Opportunities in Earth Science. National Academies Press. doi:10.17226/9981.

${ }^{3}$ Ecosystem services are the benefits people obtain from ecosystems, which include provisioning services; regulating services; cultural services; and supporting services. Millennium Ecosystem Assessment (MA). 2005. Ecosystems and Human Well-Being: Synthesis [1]. Island Press, Washington.
} 
town leaders. Most surveyed farmers preferred farm visits to learn new knowledge, while posters and written materials were the least favoured (Section 5).

From the survey results a better conceptual understanding of the science-policy-practice interface across levels of governance (i.e. county - town - village - farmer and scientists) in Yujiang County was generated from the survey. This suggested that, as part of future KE activities, more engagement between the scientists and different levels of governance to co-design training and education programmes would be beneficial for effective KE delivery. Agrotech officials at the town level can play an important and helpful role to increase KE efficiency. Furthermore, more direct communication between scientists and farmers, particularly the small farming households, is still needed in the future (Section 6).

\section{Key findings}

\section{Question 1. Sunjia catchment demographics}

- The majority of the surveyed 114 farming respondents in the villages are male (78\%). All respondents were older than 25 years old, with $58 \%$ between $41-60,41 \%$ older than 60 and only $1 \%$ of respondents between 26-40 years old. Most of them did not have much education, with $47 \%$ of the surveyed farmers were only educated to primary school and $36 \%$ to middle school.

\section{Question 2. Sunjia catchment farming and land management practice}

- Farmers identified the top issue affecting their farming practice (and thus income) was the lack of water for irrigation.

- Village and town leader data supported the farmer data also considering that water related issues (i.e. availability and quality were one of the greatest pressures on farmers). In addition, soil erosion was suggested by leaders to be more challenging to their farmers.

\section{Question 3. Environmental understanding of farming community}

- Drought (the extremely dry periods) was reported by the local farmers to be the major environment issue affecting their farming.

- While water quantity and quality are the major concerns across villages, almost $90 \%$ of the farmers did not think that their farming practice could affect water source downstream from the farm, suggesting they have limited catchment knowledge and lack understanding of how their activities impact on the environment that sustains their society.

- Similarly, the majority of farmers often left the animal waste in the field without further treatment, also suggesting that there is limited understanding of manure management and/or the impacts of their agricultural practices on their health and well-being.

Question 4. Learning and training experience and needs

- More than half of the farmers felt that they would benefit from more training to improve the productivity of their farms (and by association to lessen their environmental impact), and that the training had not been sufficient in the past.

- Farmers strongly valued on-farm visits from experts. This was their most-favoured way to learn new knowledge (96\% of respondents preferring farm visits compared to $43 \%$ favouring training courses and $35 \%$ favouring posters/picture books).

- Town level government preferred to share knowledge with farmers through providing written instruction (75\%). However most of the village leaders preferred to visit farms (60\%), which was similar to the farmers' preference.

- Other forms of KE such as posters and picture books were not popular with farmers or village level leaders. Indeed, as most of the local farmers were limited in education, written materials where reading and understanding of professional knowledge is required, may be a less viable option.

\section{Question 5. Science-policy-practice interface}


- The science-policy-practice interface in Yujiang County for knowledge sharing is mapped. It is mainly the county level office that initiates training programmes for the farmers, and the town and village level office to organise the training activities. As such, the village leaders interact more directly with farmers to provide farming advice (i.e. there is limited engagement between county level staff and farmers). Scientists are involved in the countylevel government-initiated training, but typically lack of direct communication with farmers, particularly the small farming households. The agrotech positions operated in the town level office may be a helpful role in the future KE delivery about farming impacts on the environment. 


\section{Table of Contents}

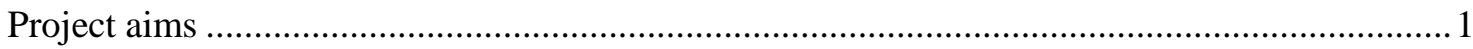

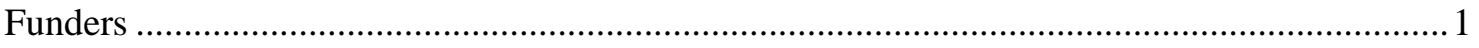

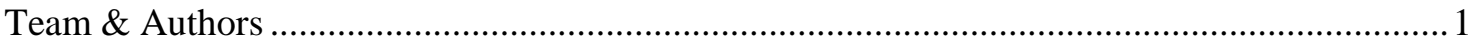

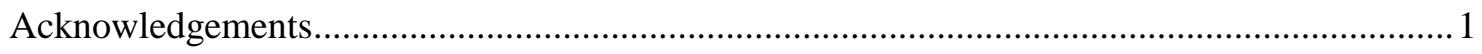

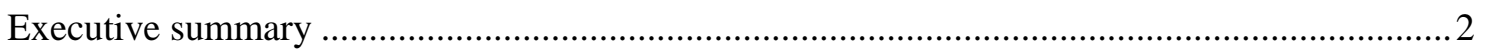

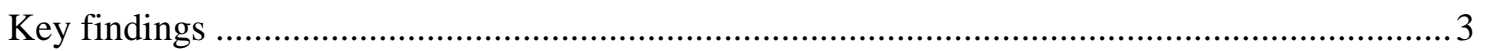

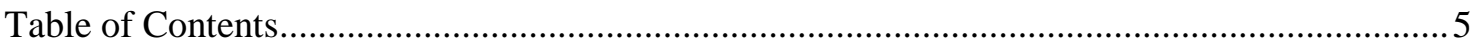

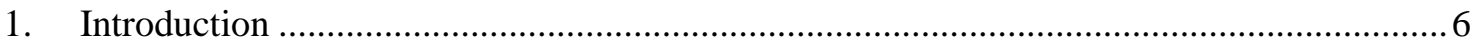

1.1 Brief introduction to the importance of CZ ecosystem................................................. 6

1.2 Rationale for the UK-China Red Soil CZ Project.................................................... 6

1.3 Summary of the CZ science activities being undertaken in Yujiang County ................. 7

1.4 Research aims of knowledge exchange (KE) in Yujiang County.................................. 7

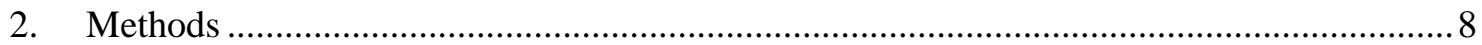

3. Demographics and farming and land management practice ............................................. 11

3.1 Demographic information about villages and farmers................................................ 11

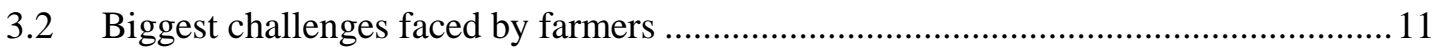

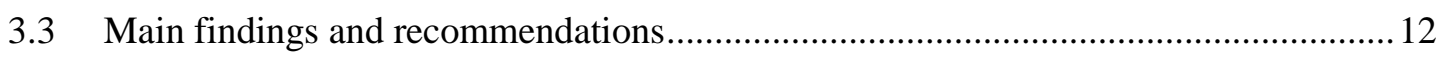

4. Catchment and human impact on the environment understanding .................................... 12

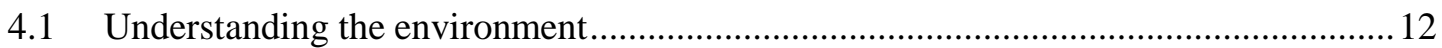

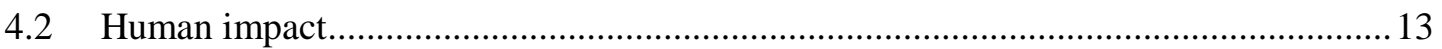

4.3 Main findings and recommendations........................................................................ 14

5. Knowledge exchange practice and learning preferences .................................................. 14

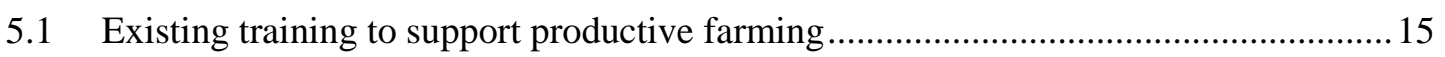

5.2 Future training interests and preferred methods of training delivery .............................. 16

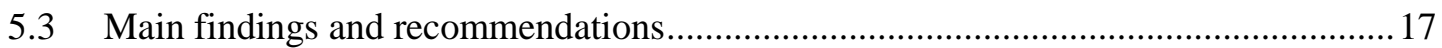

6. Science-policy-practice interface in Yujiang County …................................................... 17

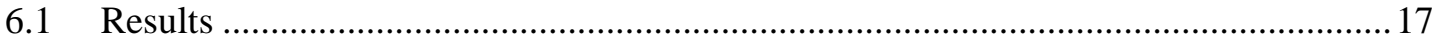

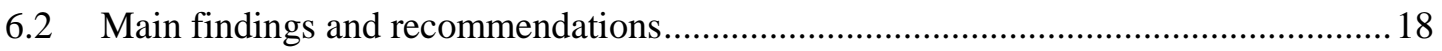

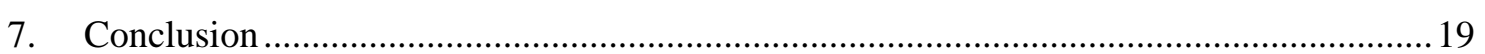

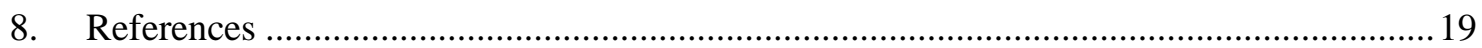




\section{Introduction}

\subsection{Brief introduction to the importance of $\mathrm{CZ}$ ecosystem}

We now understand that the surface of the Earth (the soils and vegetation) and the underlying rock (the geology) influence the quality and quantity of soil and water, which sustains critical functions for society, such as a good crop production. This portion of the Earth's surface has been scientifically termed the 'Critical Zone' (hereafter, CZ). It is considered to be a coupled chemical, biological, physical, and geological system with processes interacting to support life at the Earth's surface ${ }^{4,5}$, and supports almost all human activity from the resources it provides. The different components of the $\mathrm{CZ}$ interact and human activity can strongly influence this both positively and negatively. For ecosystems to be sustainable and productive, society needs the negative human impacts on the landscape to be reduced, through sustainable land and water management, so that the critical resources the system provides to society (e.g. food production), and activities like farming, are unaffected. However, the $\mathrm{CZ}$ can also be under pressure if it is disrupted either directly (e.g. chemical pollution) or indirectly (e.g. climate change) from human activity, and it can adversely affect its functioning and thus the economic, health and social value that society can derive from their environment. To understand how the $\mathrm{CZ}$ is affected by current human and climate stressors and how it may respond to future stressors, we need to better understand how such systems function now. Closely related to understanding how the Sunjia catchment functions scientifically is learning how society benefits from, impacts and is impacted by the current environmental conditions (e.g. how to increase crop productivity in red soils).

\subsection{Rationale for the UK-China Red Soil CZ Project}

Why in China and why study red soils: Rural China is an area of rapid population and economic growth where many people live under the poverty line. Local residents face significant environmental challenges (water quality, food production) that are currently affecting the ecosystem services that the landscape provides - and thus their current and future livelihoods. The UK-China Red Soil CZ project is a joint research programme between UK and China, which is supported by the Newton Fund ${ }^{6}$. A requirement of Newton funding is that the research must meaningfully build capacity and help alleviate poverty in developing regions of the world, in this case China.

Red soils cover $20 \%$ of China, the most populated countries on Earth. They form in sub-tropical climates where excessive leaching from rainwater has produced an infertile, unstable soil that is very vulnerable to mismanagement, climate change and pollution such as acid rain. In China, red soils support about $40 \%$ of the population, made possible through the intensive use of fertilisers to boost crop yields. This farming system is unsustainable: fertilisers reaching groundwater, freshwater and the atmosphere pose a significant environmental threat, and soil degradation through intensive cultivation can result in tens of tonnes of soil being eroded each year from a hectare of land into water courses ${ }^{7}$. Agricultural use of red soil areas of China affects the livelihood of local farmers and the surrounding population, as well as the natural ecosystem

\footnotetext{
${ }^{4}$ Lin. Earth's Critical Zone and hydropedology: concepts, characteristics, and advances. Hydrol. Earth Syst. Sci., 14, 25-45, 2010

${ }^{5}$ Brantley, S.L., Godhaber, M.B., Ragnarsdottir, K.V., 2007. Crossing disciplines and scales to understand the Critical Zone. Elements 3, 307-31.

${ }^{6}$ The Newton Fund aims to promote the economic development and social welfare of either the partner countries or, through working with the partner country, to address the well-being of communities. It will do so through strengthening partner country science and innovation capacity and unlocking further funding to support this work. China is one of the partner countries.

${ }^{7}$ Wang Y., Fan JB., Cao LX., Zheng XB., Ren P., Zhao SL., 2018. The influence of tillage practices on soil detachment in the red soil region of China. CATENA., 165, 272-278
} 
services. Thus, it is important to study red soils for national food production, and globally to alleviate negative aspects of their large environmental footprint.

\section{Why research in Yujiang County in particular?}

Although in recent years industry has been better developed in Yujiang County (e.g. copper mining and extraction), agriculture still plays an important part in the life of local villagers. However, agricultural non-point source pollution, red soil erosion and seasonal droughts here are affecting their livelihoods. This red soil CZ research project explores to understand soil processes and fertility under contrasting land management, aiming to help with the acute need of the population to improve their livelihood. This research project is using the established Sunjia CZ Observatory (CZO) in Yujiang County to gain a better understanding of red soils and their interaction with the environment, and data has been collected since 2002. In addition to the Sunjia $\mathrm{CZO}$ being an essential component for this $\mathrm{CZ}$ project delivery, it supports the current $\mathrm{CZ}$ project to build on existing monitoring to reach beyond soil processes to encompass the atmosphere, geology, groundwater, freshwater, and vegetation, which were not included in the past.

\subsection{Summary of the CZ science activities being undertaken in Yujiang County}

Although extensive research has studied red soils, particularly related to management for agricultural sustainability, the integrated effects of various affected aspects of the critical zone, as well as the wider environmental impacts are poorly understood. In this project, a critical zone approach has been adopted to reach beyond soil processes to encompass the atmosphere above, geology and groundwater below, surrounding freshwater and vegetation.

The over-arching objective of this research project is to bridge scales to disentangle how soil weathering, hydrology, biology, erosion and soil fertility of red soils interact under contrasting land management, and influence the resilience of the red soil critical zone from such perturbations in the quality and quantity of water inputs. Equally important, the scientific findings will be translated to produce outputs that inform land users and policy makers to lead to the sustainable management of red soils. This research planned will:

1. Enhance resource use efficiency (water and nutrients) for crop production on red soils from the understanding of cycling and flows to the wider environment.

2. Mitigate soil erosion, fertility losses and crop abiotic stress from a changing climate by improving the resilience of red soils to external stresses.

3. Use information systems and modelling to upscale the proposed CZO science so that evidence-based policy decisions can improve the sustainable use of red soils in China.

\subsection{Research aims of knowledge exchange (KE) in Yujiang County}

For the scientific research to benefit society (and thus fulfil the requirements of the Newton funding), it is important that the improved red soil understanding from this scientific research project reaches those who manage the environment and tend the land. To do this effectively we must gain an appreciation of who the different users of the research are, what their baseline understanding of red soil landscape is and how they like to learn. Thus, in addition to the scientific research, there is a KE project alongside the whole $\mathrm{CZ}$ programme that is designed to provide a baseline understanding of the different potential users of the outcomes of this research programme. In this red soil research project, the producers are UK and Chinese scientists, and the users are mainly government and residents who live in and manage the landscape. The KE project was funded to help understand and broker between these two groups, to better ensure that the outputs of this research fits the needs of users in Yujiang County and that a system is established to help share the new knowledge effectively. To do this, we need to engage with 
different user groups (farmers and village, town and county leaders) to better understand the following knowledge exchange research objectives:

Objective 1. To gather farm community demographics. This helps place the results of the primary research questions in the local context.

Objective 2. To understand the local farming and land management practice and their greatest pressures. This helps us to better understand which groups will benefit most from the research outputs, so that we can best align our research outcomes to their needs.

Objective 3. To assess to what extent the local community have developed their environment knowledge and understanding of human impacts. These data are crucial to identifying which scientific results will be of the greatest help to local farming communities and at what level this information needs to be pitched.

Objective 4. To identify what KE is currently carried out between the scientific and policypractitioner communities and how the user groups would like to learn about our research results. With this understanding, we can select and design the most appropriate approach to share our knowledge with different users.

Objective 5. To understand the current governance structure in Yujiang County and how is the science-policy-practice interface navigated on issues of land and farm management. This insight is crucial to identify which level of government the UK and Chinese scientists involved in this research project are best placed to share their findings.

These data we collect also serve as a baseline for future KE activities in the red soil project and/or by practitioners in China. A change in policy or farming practice may stem from the research and $\mathrm{KE}$ activities carried out in this project - by having some baseline data it may be possible for future studies to assess whether KE arising from this project leads to improved knowledge, policy or land management practices in Yujiang County. For example, we can better tailor the design for KE activities to align with what practitioners and farmers want within Yujiang County. We can also identify which gaps in their land management understanding our research findings can help address, or which farming practices such as fertiliser use may be affecting the crop productivity and negatively impacting on the soil degradation. Moreover, in 2016 a similar KE survey was carried out in Puding, Guizhou for another China-UK CZ project. Together these two reports provide valuable insights for future KE delivery that can support three China-UK CZ projects funded by NERC-NSFC.

\section{Methods}

During January and February of 2018, a comprehensive social science survey was designed and ethics approval granted for this activity by the University of Glasgow's ethics committee. Questions were refined building on those used for Puding County survey to address the five KE research objectives outlined above. The original questionnaires were developed by the scientists in the UK and Chinese teams, who were particularly involved in designing survey questions to help answer KE research objectives 2 and 3 on farming practice and environment knowledge. These questions were refined where required to fit better with the red soil management.

Between 7th - 10th March 2018, a social science survey was carried out for four levels of governance (hereafter groups) in Yujiang County: 1) county leaders, 2) town leaders (from Liuken Farm and Pingding Town), 3) village leaders (from Farm No. 3, Luwang and Hongqiao Village) and 4) individual farmers. The two towns and three villages were identified by the Chinese research team as locations within or surrounding the studied Sunjia catchment, where most of the scientific research and monitoring stations in this project are located, and where village leaders were supportive of the KE surveys. As Farm No. 3 is a large village consisting of 
eight small teams (a governance unit overseen by village), only five of the teams were chosen for the survey (Team 3, 4, 6, 7 and 8) due to the time limitations and likelihood of villagers participating. At the beginning, we interviewed females to ensure input from both genders to the survey (as roles may be different). However, female villagers were less able to answer all the questions in the survey. As such, fewer were interviewed in the later stages.

(a)

(b)

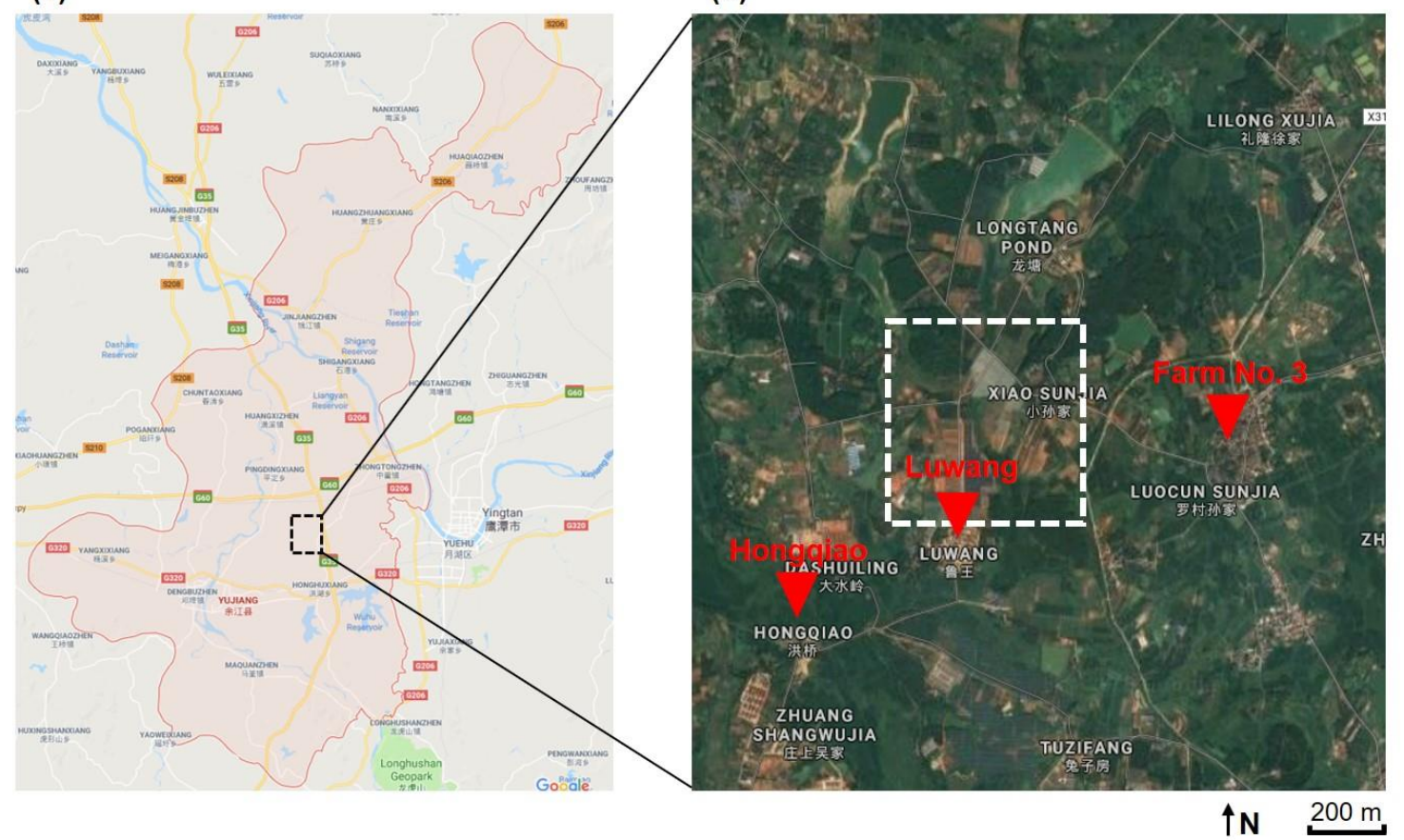

Figure 1 The map of the three villages (Farm No. 3, Luwang and Hongqiao) in Yujiang County surveyed for KE understanding (Google Map 2018). a) shows the survey area in Yujiang County. $\mathrm{In} b$ ) the white dashed line indicates generally the $\mathrm{CZO}$ filed site for red soil project.

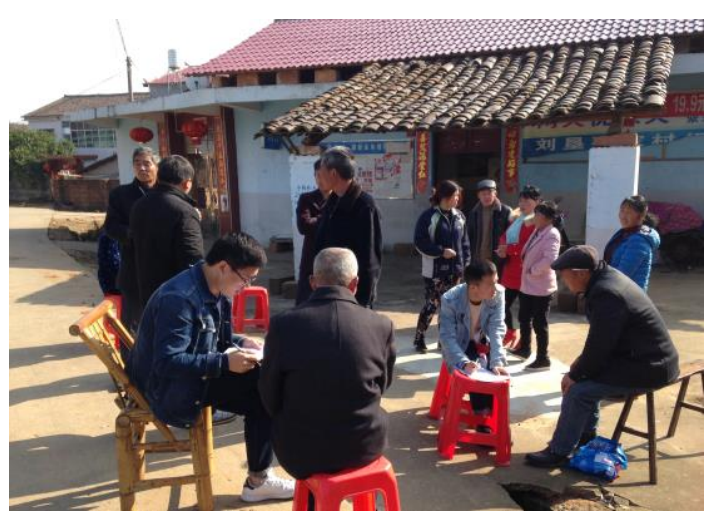

Figure 2a Local farmers filling in questionnaires with the help from students of East China University of Technology.

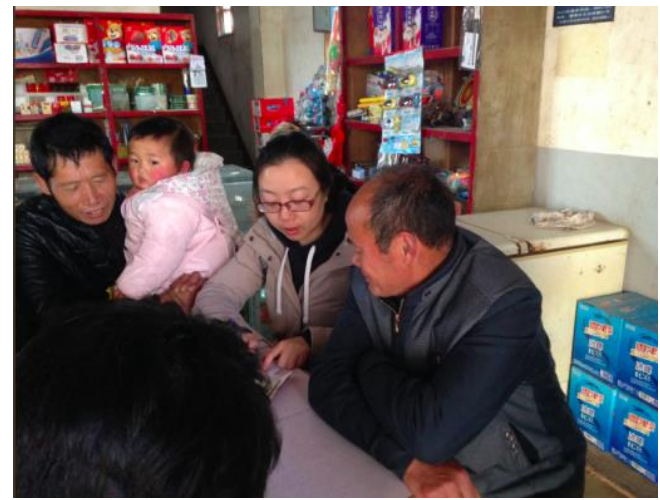

Figure 2b Farmers were gathered for surveys carried out by the UK researcher.

As part of this work package, we also sought to build knowledge and skills of local Chinese university students. Three students from East China University of Technology attended a halfday training course led Dr. Ying Zheng, researcher from the University of Glasgow, and then served as research assistants for the survey. In the field they assisted farmers with understanding and completing questionnaires (Figure 2a). In total a maximum of 114 responses were collected 
from farmers, 8 from village leaders, 4 from town leaders and 3 from county leaders (错误!书签 自引用无效。).

Questionnaires with both closed and open-ended questions were the main survey method for all groups. Between 20 - 69 questionnaires were completed in each village dependent on its population. The total number of survey questions per group and research question are outlined in

Table 2. In addition to surveys, semi-structured individual interviews were also conducted with government leaders from county, town and village levels. The number of leaders interviewed varied between village and town (from one - five people), depending on the number of leaders who were available. At county level, three government officials were interviewed. In this report the data from questionnaire survey and interview are combined for science-policy-practice understanding and not presented individually.

Table 1 The number of farmers and government leaders in Yujiang County surveyed or interviewed.

\begin{tabular}{|c|c|c|c|c|c|}
\hline & \multirow{3}{*}{ Groups } & \multicolumn{3}{|c|}{ Yujiang County } & \multirow{3}{*}{ Total } \\
\hline & & \multirow{2}{*}{$\begin{array}{c}\text { Liuken Farm } \\
\text { Farm No. Three }\end{array}$} & \multicolumn{2}{|c|}{ Pingding Town } & \\
\hline & & & Luwang & Hongqiao & \\
\hline Questionnaire & Farmers & 69 & 25 & 20 & 114 \\
\hline \multirow{3}{*}{$\begin{array}{c}\text { Questionnaire } \\
\text { \& Interview }\end{array}$} & Village leaders & 5 & 2 & 1 & 8 \\
\hline & Town leaders & 3 & \multirow{2}{*}{\multicolumn{2}{|c|}{1}} & 4 \\
\hline & County leaders & & & & 3 \\
\hline
\end{tabular}

Table 2 Summary of survey questions by group and research question where leader surveys were carried out for three levels of governance (county, town and village).

\begin{tabular}{lccc}
\hline $\begin{array}{l}\text { Category of survey } \\
\text { questions }\end{array}$ & $\begin{array}{l}\text { Farmer survey, } \\
\text { no. of questions }\end{array}$ & $\begin{array}{l}\text { Town and village } \\
\text { leader survey, } \\
\text { no. of questions }\end{array}$ & $\begin{array}{l}\text { County leader } \\
\text { survey, no. of } \\
\text { questions }\end{array}$ \\
\hline $\begin{array}{l}\text { Total number of questions } \\
\text { Question 1. Demographics }\end{array}$ & 34 & 18 & 20 \\
$\begin{array}{l}\text { Question 2. Farming/land } \\
\text { management practice (e.g. }\end{array}$ & 10 & 4 & 4 \\
fertiliser management) & & 4 & 1 \\
$\begin{array}{l}\text { Question 3. Environment } \\
\text { understanding }\end{array}$ & 5 & & \\
$\begin{array}{l}\text { Question 4. learning/training } \\
\text { Question 5. Science-policy- } \\
\text { practice interface }\end{array}$ & 16 & 3 & 3 \\
$\begin{array}{l}\text { Question 6. Job background } \\
\text { Question 7. Policy making }\end{array}$ & & 8 & 8 \\
\hline
\end{tabular}

In this report we provide a high-level summary of the understanding of the surveyed residents, farmers and leaders in Yujiang County, thus the data is grouped for presentation in the level of town and village. More detailed analysis considering similarities and differences within groups, such as comparisons between different villages and towns, could form a part of a larger study. 


\section{Demographics and farming and land management practice}

All groups surveyed were asked some basic demographic questions. Farmers were also asked about their own farming and land management practices, and leaders were asked about the activities of farmers in their communities. The most pertinent results from these questions are presented in this section.

\subsection{Demographic information about villages and farmers}

The majority of 114 farming respondents surveyed in the villages were male (78\%). All respondents were older than 25 years old, with $58 \%$ between $41-60,41 \%$ older than 60 and only $1 \%$ of respondents between 26-40 years old. Most of them did not have much education: $47 \%$ of the surveyed farmers were only educated to primary school and $36 \%$ to middle school. This is an important understanding to be considered when designing KE approaches to be more accessible.

\subsection{Biggest challenges faced by farmers}

Data was collected on farmer and village and town perspectives on the greatest pressure on farmers within their jurisdictions. For Yujiang farmers, sufficient water available for irrigation and/or good quality was the greatest concern (suggested by $34 \%$ ). The next three concerns had similar levels of responses: lack of technology (15\%); the implementation of government regulations $(14 \%)$ and the lack of labour $(12 \%)(n=114$, Figure 3$)$.

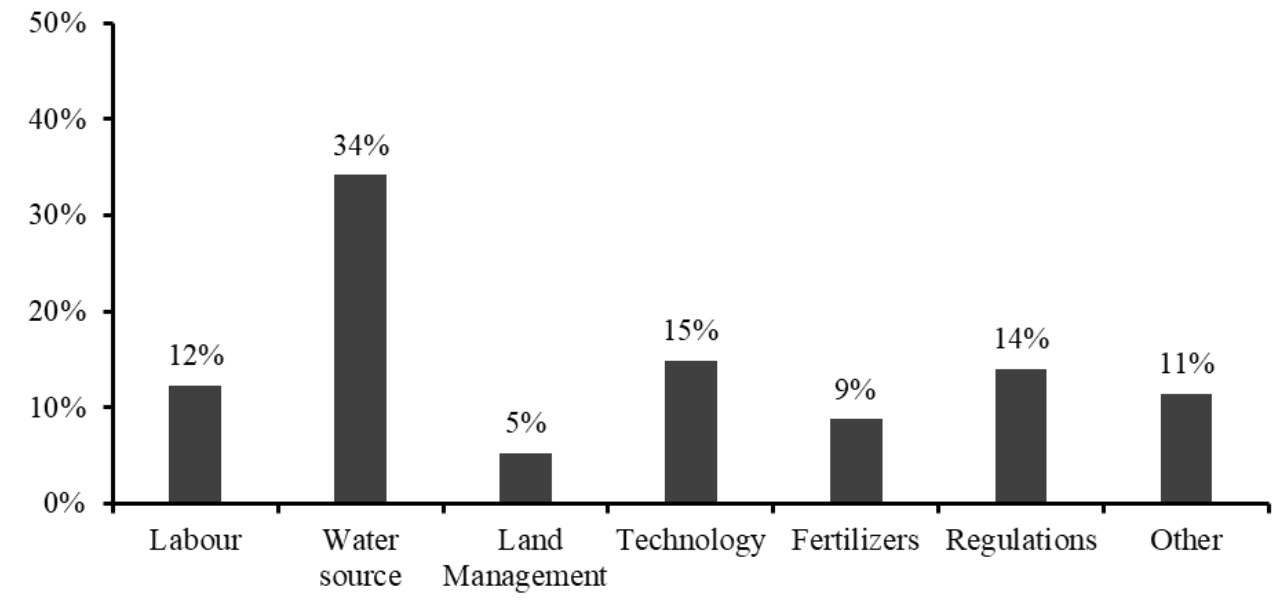

Figure 3. Farmer survey Q31: The biggest challenge for local farmers in farming $(n=114$, multiple answers provided by farmers).

However, different from the farmers' responses, both village and town leaders considered the declining soil quality was the greatest pressures on their farmers $(75 \%$ of village leaders $(n=8)$ and town leaders $(\mathrm{n}=4)$ ). Water-related issues were suggested by $50 \%$ of the town leaders as the greatest pressure, while earning an income (38\%) was of greater concern than water problems $(25 \%)$ to the village leaders.

When farmers were asked about what the most expensive part of their farming activity was, it was apparent that fertilisers were the greatest expense (reported by $88 \%$ of 114 farmers), followed by tools and chemicals, respectively (Figure 4). This suggests that whilst water source is the greatest perceived challenges for farmers, the greatest expense is fertilisers. This correlates well with the leader surveys that found earning an income was the greatest pressure for farmers by some of the leaders (village: $38 \%$; town: $25 \%$ ). The farmers thus appear to have two key pressures: water-related issues and the cost of fertilisers. 


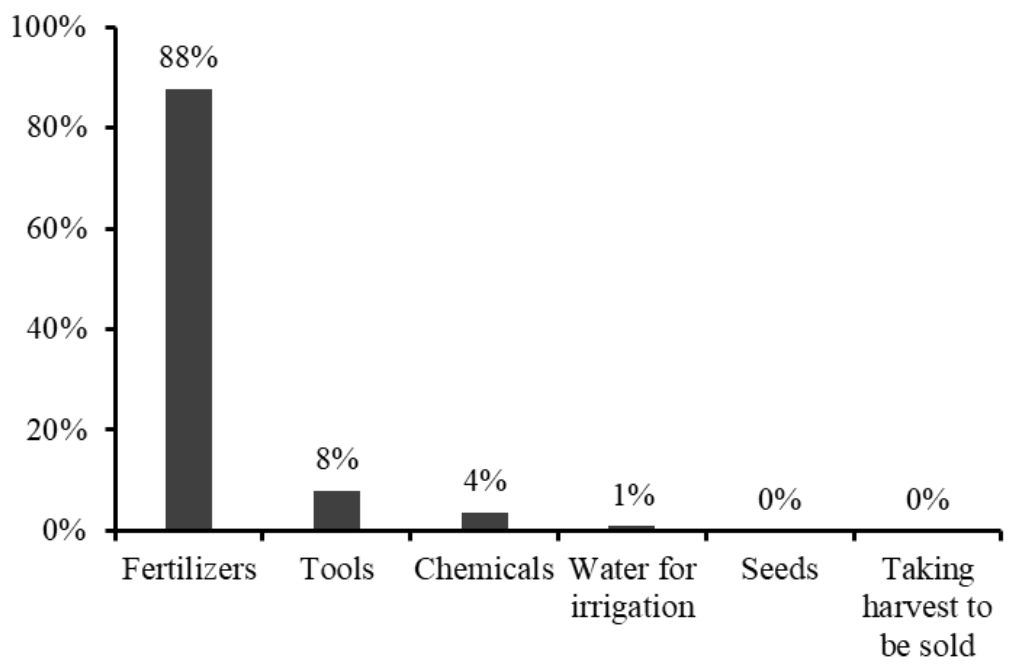

Figure 4. Farmer survey Q32: What is the most expensive part of your farming activities? $(\mathrm{n}=114$, respondents could choose more than one answer if they considered of equal expense)

Farmers were then asked what types of support and interventions could help improve the productivity and/or income generating capacity of their farms. The majority of respondents in all villages selected three of the five options: more financial support, more land and more training.

\subsection{Main findings and recommendations}

- In the surveyed villages in Yujiang County older residents are maintaining the land. This is a consistent and common trend in China due to an increasing number of young people working in cities. The villagers' age and the potential links with education level, may have impacts on how best to communicate and share new farming knowledge.

- Both farmers and some of town/village leaders reported water-related issues (quantity and quality) were the biggest challenge affecting their farming practice (and thus income), suggesting a need to improve water availability and quality for the better local agriculture development and farmers' life. Farming advice on effective water use for irrigation and for how to improve water quality via chemical/fertiliser management, would be helpful and much needed. This hydrological insight is also crucial as soil and water are closely linked in ecosystems, and the water quantity and quality reflect soil processes to some extent (e.g. intensive cultivation can result in soil being eroded and lost to water courses).

- In terms of farming cost, buying fertilizers was overwhelmingly the most expensive component. In addition, most of both village and town leaders suggested declining soil quality was the greatest pressures on their farmers. Intensive use of fertilizers for cultivation can greatly lead to soil degradation and thus quality. Therefore, advice on how to reduce the use of fertilizers is needed to lessen the unnecessary expense from farmers, to boost their revenue and to protect the environment on and off farm.

\section{Catchment and human impact on the environment understanding}

This topic was addressed in two ways: 1) catchment understanding - to assess how well farmers understand how their local landscape works and 2) human impact - to gauge their awareness of whether their activities influence their environment.

\subsection{Understanding the environment}

Farmers were asked if they had ever heard about the term of 'red soils'. More than half of the respondents (54\%) reported no and $25 \%$ said they only heard about it occasionally. Less than $10 \%$ of the surveyed farmers heard about 'red soils' often. These may be the farmers closely interacting with the red soil researchers, e.g. the farmer's land was rented by the scientists from Yujiang Station for fieldwork. However, it should be noted that the local farmers had their own 
understanding about red soils. For example, they knew the soils were special in having a dark red colour and had named them in the local dialect.

When asked about local environmental issues, farmers were concerned about water availability with $61 \%$ (total $n=114$ ) confirming 'drought' was affecting their farming (Figure 5). Thirty-five percent of farmers across villages said flooding was another factor affecting farming. However, soil erosion, forest fire and landslides did not appear often as concerns to the farmers in these surveyed villages.

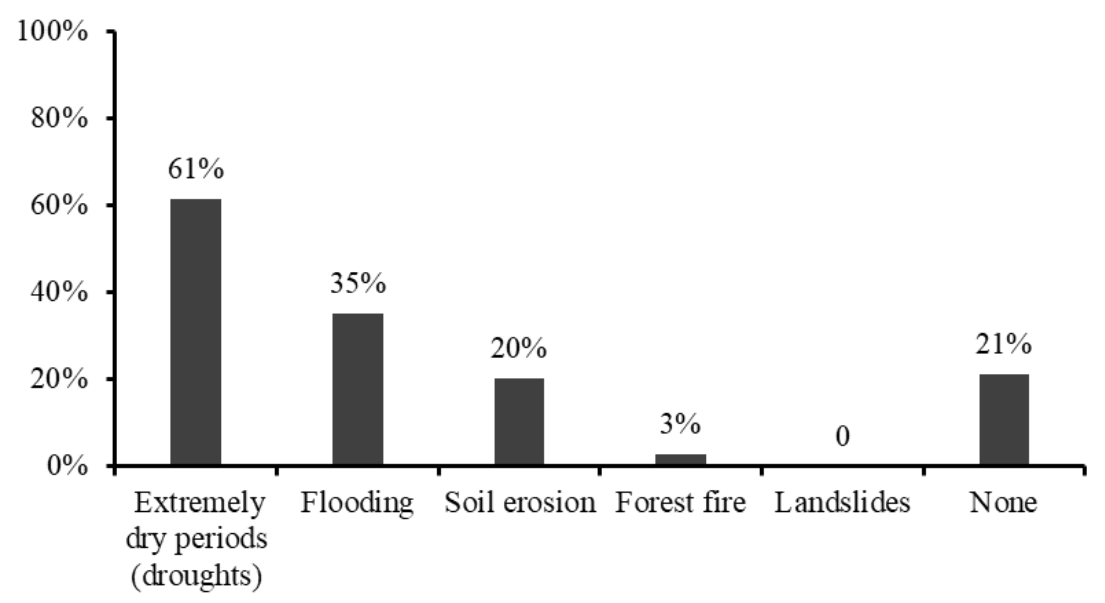

Figure 5. Farmer survey Q28: What types of environmental issues affect your farm? $(\mathrm{n}=114$, multiple choice)

\subsection{Human impact}

The question of whether farmers thought their farming activities (e.g. tilling, fertiliser use) would affect water source downstream from their land, can help to gauge farmers' scientific or tacit understanding about their wider environment and catchment. Across all villages, the majority of the farmers suggested no such effects from their farming ( $86 \%$ of $n=114$ ) (Figure 6), suggesting they have limited catchment knowledge and lack understanding of how their activities impact on the environment that sustains their society.

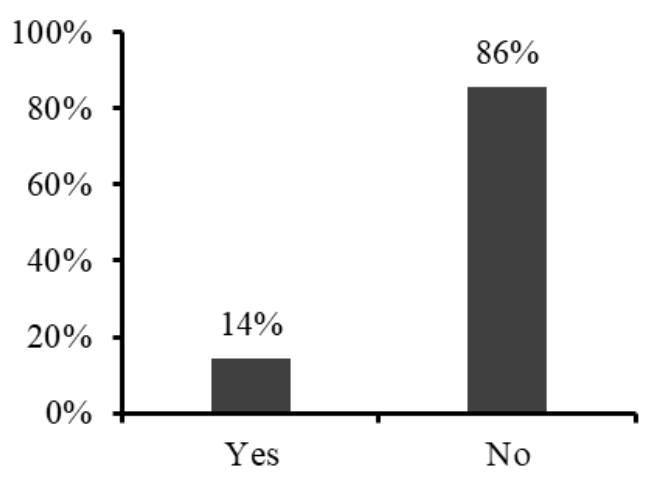

Figure 6. Farmer survey Q16: Do you think any of the farm activities (e.g. tilling, fertiliser or chemical use) you do on your land affect anything down the hill from your farm? $(\mathrm{n}=$ 114)

Farmers were also asked if they had been encouraged to manage fertilizer and/or manure, and $79 \%$ of the surveyed farmers (total $n=113$ ) reported no such experience. Furthermore, we asked the farmers who kept farm animals $(n=58)$ how they dealt with animal waste. The majority of them (86\%) reported they left it in a pile in the field to become manure, with only 3-5\% of them placing it indoors to produce manure or carrying it to a biogas tank (Figure 7). Five percent of farmers left the animal waste where it was deposited with no further treatment or use and no farmers reported they washed the waste directly into drains or watercourses. 


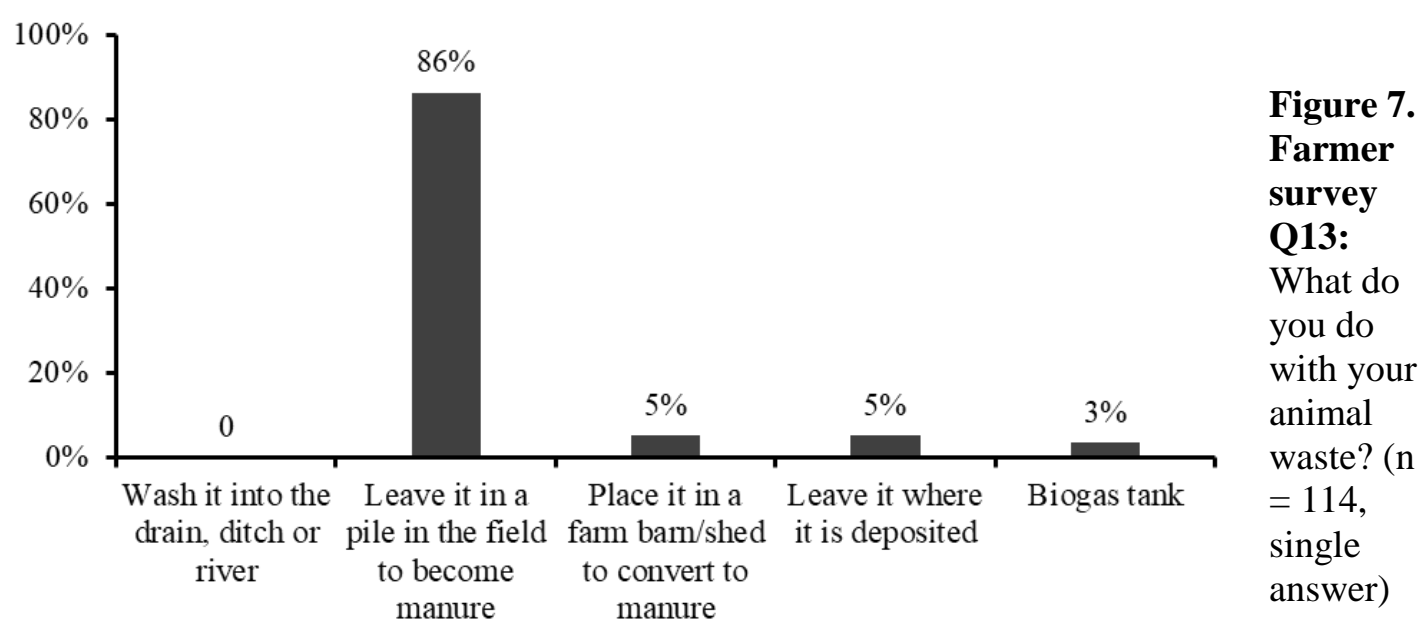

\subsection{Main findings and recommendations}

- The farmers' concerns with water quantity for irrigation come with the frequent droughts in these villages. Although less often reported, flooding is another issue affecting farming. These concerns indicate that scientific research is needed to help understand water availability to better deal with droughts and the risk of soil erosion during flooding to improve and sustain ecosystem services.

- Farmers in these villages have limited environmental knowledge. Thus the relevant education or training may encourage them to foster better farming practice to protect their local ecosystem.

- Due to the fertiliser cost and its damage to soil and water quality, training and promotion of fertiliser management to farmers would be recommended to develop an economic and environmental-friendly way to use fertiliser. This may help to reduce red soil degradation, and improve water quality, as well as reduce the greatest economic pressure (i.e. fertilisers) on local farmers.

\section{Knowledge exchange practice and learning preferences}

In response to this topic, farmers (Table 3) and government leaders (Table 4) were asked respectively to describe: 1) the current farmer training situation (e.g. how much training was provided to farmers, and existing training methods), and 2) what learning methods were preferred by farmers.

Table 3 Overview of questions used in the farmers' survey related to KE practice

\begin{tabular}{lc}
\hline Category & No. \\
\hline Existing KE practice & 3 \\
Interest/need in learning & 6 \\
Preferred methods & 1 \\
Barrier to learning & 1 \\
Total & 11 \\
\hline
\end{tabular}

Table 4 Overview of questions used in leader committee's survey related to KE practice

\begin{tabular}{lc}
\hline Category & No. \\
\hline Experience in KE with farmers & 3 \\
Experience in/suggestions for & 6 \\
KE with scientists & 5 \\
Implementing policy & 3 \\
Making policy & 17 \\
\hline Total & \\
\hline
\end{tabular}




\subsection{Existing training to support productive farming}

We assessed how farmers are currently trained/supported to improve their farm practices, and asked town/village leaders about what advice for new/improved farming practice was provided to the farmers. About half of the farmers from all villages $(46 \%$ of total $n=114)$ indicated no financial or training-related support (Figure 8). Of the farmers who had received support to help improve their farming practice, $47 \%$ were financially-supported whilst only $10 \%$ received training.

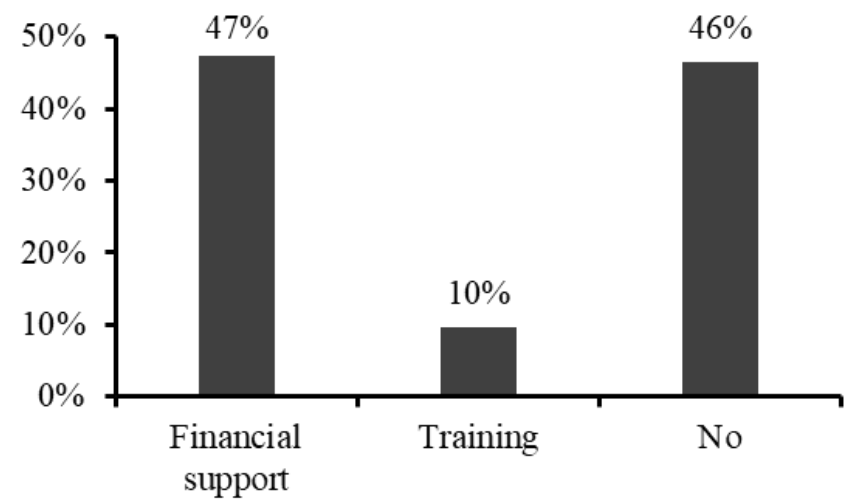

Figure 8. Farmer survey Q18: Have you ever received training or financial support from the government before? If yes, what kind of support have you been given? $(\mathrm{n}=114$, multiple choice $)$

Most of the town and village leaders reported they had provided advice on new farming practices to farmers ( 3 out of 8 village leaders had no such experience). In general, there was a consistency between town and village leaders about what sort of advice was given, with most advice provided about water conservation, new farming techniques, fertilizer use and manure management. This perspective differed from the farmers' response, which suggested most of them (79\% of 113) were not encouraged to manage fertilizer and/or manure. In addition, farmers reported they had had limited advice from leaders for soil conservation (village: 20\%, town: $25 \%$ ) and/or soil erosion (village: $20 \%$, town: $50 \%$ ).

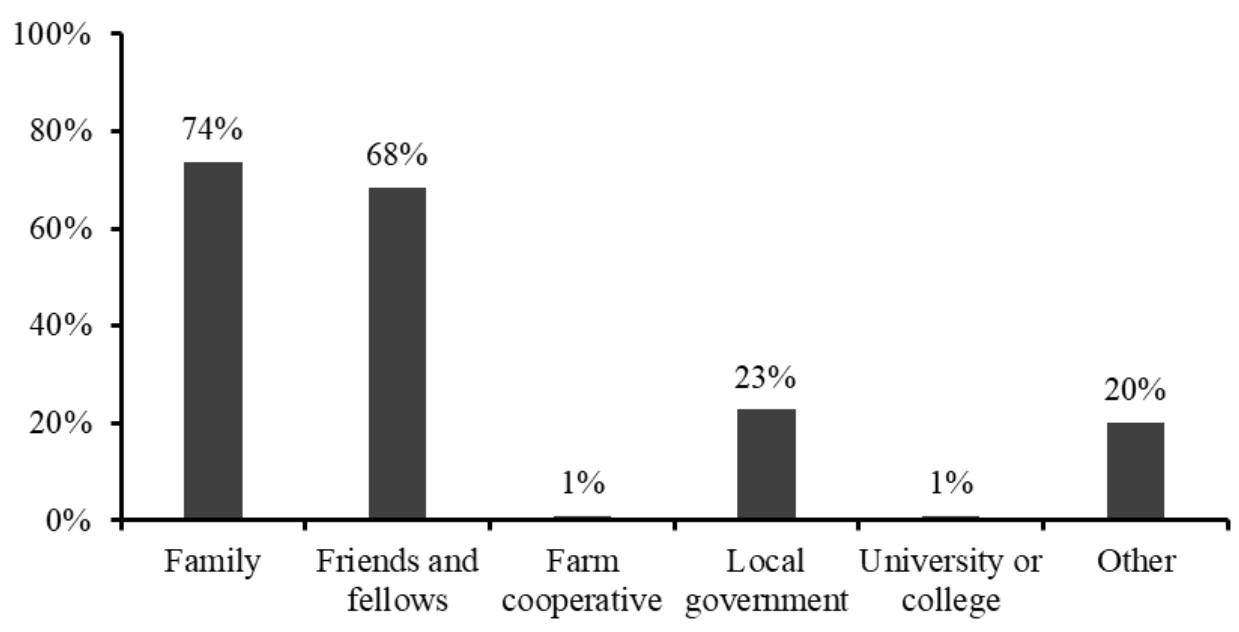

Figure 9. Farmer survey Q7: Where do you currently learn about farming methods? ( $\mathrm{n}=114$, multiple choice)

While advice on farming practices was provided by local leaders, family and friends still played a fundamental role in spreading farming knowledge, with most of the surveyed farmers (74\% and $68 \%$ of $\mathrm{n}=114$ respectively) reporting they learned farming methods from these groups (Figure 9). Only about $20 \%$ of farmers suggested they also learned farming methods from local government (including government agencies from city to village) - another indicator of little 
training support the farmers think they have received from the government. Very few farmers $(1 \%)$ reported learning farming from university or college. However, some farmers also learned farming in other ways, including self-learning by reading and learning from the technician employed by the agri-business farms where the farmers also worked in.

\subsection{Future training interests and preferred methods of training delivery}

Importantly, when farmers were asked if they would like to receive future training to help them farm differently, the response was overwhelmingly positive with $73 \%$ of all surveyed farmers (n $=114)$ supporting future training. Similarly $67 \%$ of the farmers $(n=114)$ were very interested/interested in learning about red soil erosion risks on their farms and 61\% (of $n=104$ ) about red soil management. While $12 \%$ of the respondent farmers (total $\mathrm{n}=95$ ) said there was no difficulty for them to participate in training activities, about $50 \%$ reported they could not afford to take time away from the farm and/or their family (e.g. some farmers needed to take care of children).

Town and village leaders were also asked about the best ways to support farmers to change their farming practice in the future. The response of leaders between town and village level of governance varied. The majority of town leaders interviewed (3 out of 4) felt training was a key method for improving farm practice, while financial support was not suggested by any of the town leaders. However, among the village leaders $(n=8)$, half of them suggested that financial support for farmers was the most crucial way, whilst $25 \%$ of them felt training was the best route.

Farmers' preferences to learn new farming knowledge were different from the current training approaches used by government leaders. Farmers from all villages were nearly unanimous $(96 \%$ of total $n=92$ ) that farm visits were the best training method. The next three most popular methods with farmers were attending a training course (43\%); reading poster/picture book $(35 \%)$ or written instructions (28\%) (Figure 10).

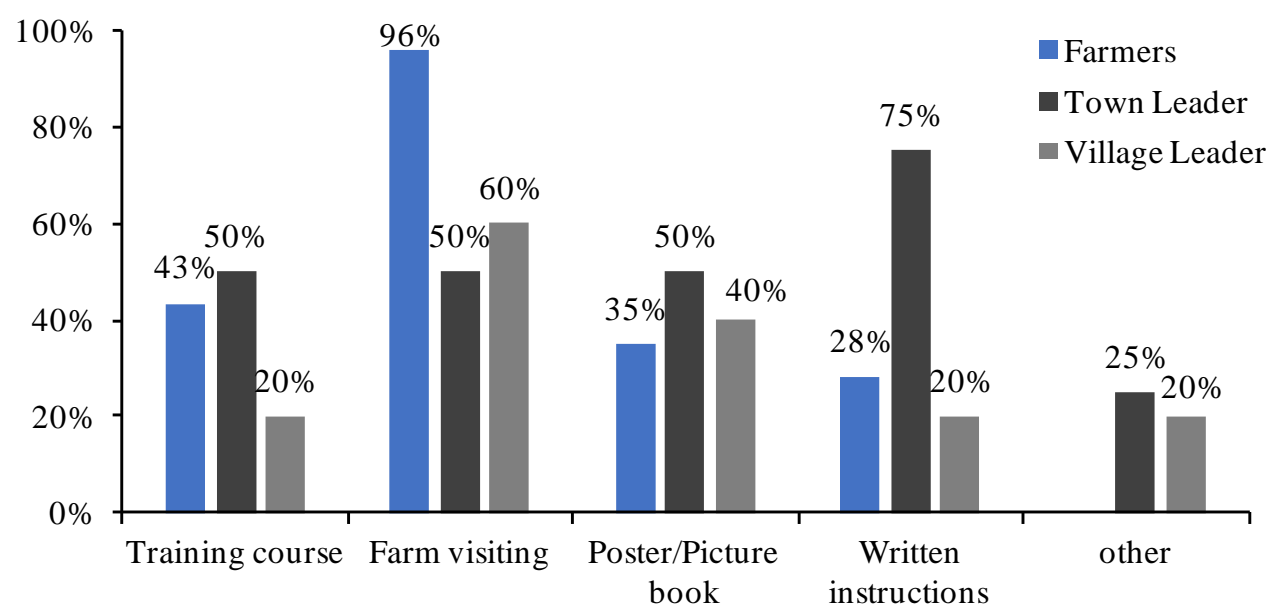

Figure 10. Farmer survey Q25 and village/town leader survey Q8: methods preferred by farmers to learn different farm practice/knowledge, and methods currently used by government leaders to provide advice on new farming practice (respondents could choose more than one answer).

For town leaders, written instructions were the most popular way currently used to provide farmers with advice on farming practice ( $75 \%$ of $n=4$, Figure 10$)$, followed by trainings course, farm visits and poster/picture book (all by $50 \%$ of the town leaders). This contrasts with farmers who felt written instructions were the least favoured modes of training. 
Village leaders showed a broadly similar preference with farmers of these different methods, with most of them (60\% of $n=8)$ currently using farm visits to share knowledge (Figure 10). More village leaders felt that posters and picture books $(40 \%)$ were effective to provide farming advice than providing training course (20\%) and written instructions (20\%). This is more consistent with the farmers preferences for on farm visits, but with differences for the remaining approaches to share information across the three groups surveyed.

\subsection{Main findings and recommendations}

- More effective training for improved, ecologically-sensitive farming will be required, as it appeared that about half of the farmers do not believe they received any kind of government support, and family, friends and fellow farmers are still the major source of farming knowledge.

- Training to improve sharing/learning processes between farmers and the government can help to promote productive farming and environmental knowledge. However, only $10 \%$ of the farmers had received training from the local government. As the most of farmers would welcome more training for farming, this training from the government is strongly recommended.

- The data show some differences of opinion between levels of government on the best methods of supporting farmers improving their environmental and farming knowledge. The preferred ways of sharing/learning are apparent from this survey and thus provide important insight into future government-public communication about farming practice.

- Instead of written instructions, which were often used by the town level government to share new farming practice, farm visiting by experts and talking in person on farms is strongly preferred by farmers and so this should be considered. Furthermore, reading materials including posters, picture books and written instructions are not preferred in sharing knowledge and so may not be particularly effective and this should not be a primary approach.

\section{Science-policy-practice interface in Yujiang County}

\subsection{Results}

An understanding of how groups of scientists, government officers and practitioners interact and collaborate with each other was generated from the semi-structured individual interviews with the local government leaders.

In the process of knowledge delivery, a hierarchy between different levels of government appears to exist, and leaders from multi-levels have different job roles. The province/city offices make high-level local policies for the environment and farming practice. For example, the welldeveloped Jiangxi Academician Workstation scheme, which aims to better foster local science and technology development, is a policy decision approved programme, and is strongly supported by the provincial government. This policy actively facilitates the rice-based cultivation models promoted in Yingtan City (which oversees Yujiang County under its administration). In addition, the high-level offices also work to facilitate the collaboration between the academic community and government by appointing a few local research institutes and universities for supporting science knowledge communication. These include, e.g. Jiangxi Academy of Agricultural Sciences and Jiangxi Agricultural University. This may indicate the Yujiang government has a strong and stable collaboration relationship with the local research community that could be further applied (e.g. to provide direct science communication for the local farmers). Apart from making policy, the province/city offices also provide funding for any proposed and permitted training events. 


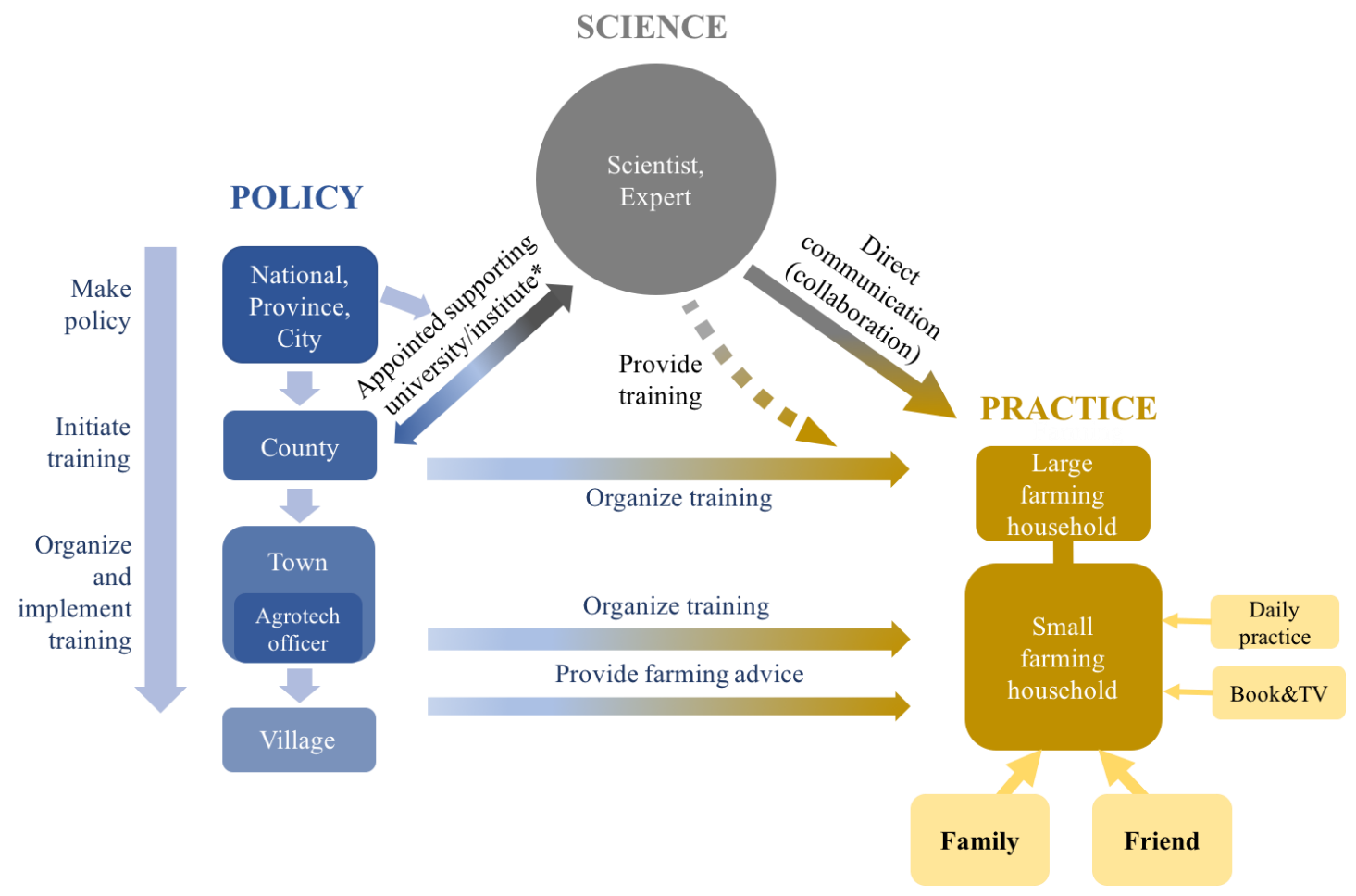

* e.g. Jiangxi Academy of Agricultural Sciences, Jiangxi Agricultural University

Figure 11. Science-policy-practice interface during knowledge exchange process in Yujiang County.

County leaders perform the similar role in granting funding, although instead of making policies, they form local regulations. It is more of the job for town and village leaders to take information from these policies and regulations to their next level, to communities and ultimately to farmers. Therefore, village leaders are those interact directly with farmers and are better placed to provide advice on farming activities. Most training for farmers is initiated by county leaders and passed to and organised by town/village leaders. Additionally, at the town level there is an agrotech officer position specifically designed to provide advice and help to local farmers. When well supported, this will be a useful government role to promote more efficient knowledge exchange for the local farmers.

Within the farming community, large farming households often receive direct training support from the local government (sometimes directly from the county level), before individual farmers did. This is to increase the training efficiency and outcomes, as there is limited training funding. However, it inevitably decreases the learning opportunities for the small farming households. Furthermore, direct communication occurs between scientists and large farming household via establishing collaboration. Scientists get involved with the small farming households too, by providing training courses organised by the local government. Clearly this communication exists depending on the arrangement by the government and thus may reduce the efficiency of knowledge flow in this interface.

\subsection{Main findings and recommendations}

- Our survey clearly identifies the different job roles of each governance level. Combined with the survey results of farmers' learning preference shown in the earlier sections, this provides some clarity for scientists to identify which levels of governance to collaborate with to create more KE opportunities, and what modes of training are best suited to work with local practitioners to exchange farming and environment knowledge. 
- A two-way knowledge sharing between scientists and users is recommended for all levels of governance. More engagement between scientists and county level offices is largely encouraged. This will helpfully facilitate the communication between the two groups to codesign new policies and initiate education and training programmes for town, village and farmer governance levels to improve farm productively and reduce farming impacts on the environment. Furthermore, 3) funding opportunities available at the county government for KE delivery are important information for the scientists.

- The two-way knowledge sharing can be further carried out by working with farmers and town/village leaders to co-design training activities for farmers. The agrotech officials can be helpful in increasing KE delivery efficiency and thus it may be worthy involving them in the science communication process.

- It would be beneficial to create more opportunities and channels to facilitate more direct communication with scientists/experts for both large and small farming households. This can help ensure that the training/knowledge shared properly meets the needs of farmers.

\section{Conclusion}

This report documents a better understanding about the local science users in the three surveyed villages in Yujiang County, the KE approach preferred by different user groups, and the sciencepolicy-practice interface during KE process. This KE understanding can be shared with the local government at different levels, with the primary aim being to facilitate a more effective communication between government and local farmers.

In addition, these important findings of Yujiang KE delivery from this report has been compared with those from a similar survey conducted in Puding, Guizhou (the field site for two other NERC-NSFC founded projects) in November 2016. The understanding of these two KE surveys has been summarised to form a report for the wider China-UK CZ program, which presents the similarities and differences of conducting KE in two Chinese provinces and provides important suggestions for how to better deliver KE in Chinese rural areas in the future.

\section{References}

Brantley, S.L., Godhaber, M.B., Ragnarsdottir, K.V., 2007. Crossing disciplines and scales to understand the Critical Zone. Elements 3, 307-31.

Cvitanovic, C., Hobday, A.J., van Kerkhoff, L., Wilson, S.K., Dobbs, K., Marshall, N.A., 2015. Improving knowledge exchange among scientists and decision-makers to facilitate the adaptive governance of marine resources: A review of knowledge and research needs. Ocean \& Coastal Management 112, 25-35.

Fazey, I., Evely, A.C., Reed, M.S., Stringer, L.C., Kruijsen, J., White, P.C.L., Newsham, A., Jin, L., Cortazzi, M., Phillipson, J., Blackstock, K., Entwistle, N., Sheate, W., Armstrong, F., Blackmore, C., Fazey, J., Ingram, J., Gregson, J.O.N., Lowe, P., Morton, S., Trevitt, C., 2013. Knowledge exchange: a review and research agenda for environmental management. Environmental Conservation 40, 19-36.

Lin. Earth's Critical Zone and hydropedology: concepts, characteristics, and advances. Hydrol. Earth Syst. Sci., 14, 25-45, 2010.

Millennium Ecosystem Assessment (MA). 2005. Ecosystems and Human Well-Being: Synthesis [1]. Island Press, Washington.

Wang Y., Fan JB., Cao LX., Zheng XB., Ren P., Zhao SL., 2018. The influence of tillage practices on soil detachment in the red soil region of China. CATENA., 165, 272-278 